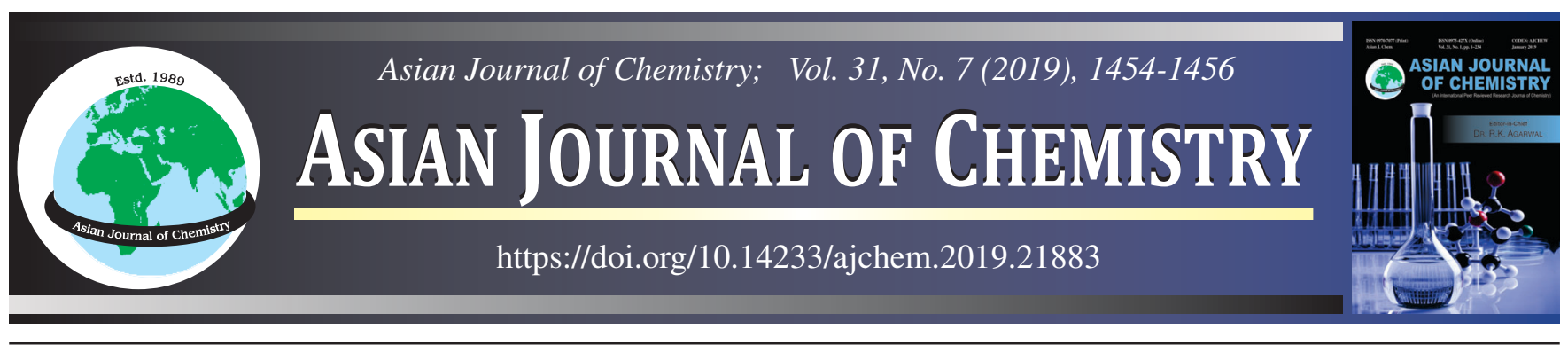

\title{
Mixed Micellar Cloud Point Extraction and Spectrophotometric Determination of Meldola's Blue Dye in Tap and Sea Water Samples
}

\section{Suneetha ${ }^{1}$, P. Shyamala ${ }^{2, *}$ and SK. Ameer Khan ${ }^{2}$}

${ }^{1}$ Department of Chemistry, Government Degree College, Yeleswaram-533429, India

${ }^{2}$ Department of Physical and Nuclear Chemistry \& Chemical Oceanography, School of Chemistry, Andhra University, Visakhapatnam-530003, India

*Corresponding author: E-mail: shyamalapulipaka06@gmail.com

Received: 18 December 2018;

Accepted: 15 January 2019;

Published online: 21 May 2019;

AJC-19394

A simple and new mixed-micelle cloud point extraction procedure has been developed for the extraction of Meldola's blue dye. A mixed micelle consists of Triton X-114 and docusate sodium salt at a pH of 4.5 in the presence of $\mathrm{Na}_{2} \mathrm{SO}_{4}$. The various parameters show effect on extraction of dye like $\mathrm{pH}$, concentration of Triton $\mathrm{X}-114$, concentration of docusate sodium salt, concentration of $\mathrm{Na}_{2} \mathrm{SO}_{4}$, equilibrium temperature and equilibrium time were optimized. Under optimum conditions the linear range of dye Meldola's blue was found to be $0.0-11.17 \mu \mathrm{g} \mathrm{mL}^{-1}$. The corresponding detection limit was found to be $0.00311 \mu \mathrm{g} \mathrm{mL}^{-1}$. The proposed method has been successfully applied to the extraction of Meldola's blue dye in tap water and sea water. The recoveries were found to be in the range of 85.79-93.13\%.

Keywords: Mixed micelle, Meldola's blue, Triton X-114, Docusate sodium salt

\section{INTRODUCTION}

Synthetic dyes are used in textile, leather, paper, pharmaceutical and food industries which are continuously entering into the ecosystem. These dyes are hazardous in nature and therefore monitoring of environmental samples for trace determination of organic dyes [1,2] and their removal $[3,4]$ is very important in the recent times. Due to the low concentration of dyes in water and to obtain accurate quantification results, it is necessary to eliminate the unwanted matrix effects and hence pre-concentration is required before subjecting the samples for instrumental analysis. Some pre-concentration techniques include solvent extraction [5], solid phase extraction [6], dispersive liquid-liquid micro extraction (DLLME) [7-9] and cloud point extraction (CPE) [10-13].

Among these techniques, cloud point extraction (CPE) is recognized as an efficient technique for hydrophobic species in solution phase. The aqueous solution of surfactants are heated at a certain temperature they become turbid and separate into two distinct phases, aqueous phase and surfactant rich phase. Depending on the solubility of a solute in the surfactant it is entrapped in the surfactant rich phase during separation. The two phases are separated by centrifugation and thus the solute pre-concentration is achieved. The concentration of the solute present in the surfactant rich phase is then determined by different analytical methods. This method is called cloud point extraction method (CPE) and the temperature is called cloud point temperature. The CPE method has been well investigated using single pure surfactant like Triton X-114 [14,15] but CPE methods are only slightly explored in the presence of mixed micelles. Mixed micelle cloud point extraction based on mixing either cationic or anionic surfactants with non-ionic surfactants exhibit better performance and synergism compared to single surfactant due to higher surface activity. In this work, a simple and new mixed micelle cloud point extraction procedure for the extraction and pre-concentration of Meldola's blue dye using Triton X-114 and docusate sodium salt is reported.

\section{EXPERIMENTAL}

All reagents used were of analytical grade and double distilled water used throughout the experiments. Stock solution of $10 \% \mathrm{w} / \mathrm{v}$ Triton X-114 (polyethylene glycol tert-octylphenyl

This is an open access journal, and articles are distributed under the terms of the Creative Commons Attribution-NonCommercial-ShareAlike 4.0 (CC BY-NC-SA 4.0) International License which allows readers to freely read, download, copy, distribute, print, search, or link to the full texts of its articles and to use them for any other lawful non-commercial purpose as long as the original source is duly acknowledged. 
ether, Sigma-Aldrich, USA) was prepared in double distilled water and $10 \% \mathrm{w} / \mathrm{v}$ docusate sodium salt (Fluka, USA) was prepared in methanol. Stock solution of Meldola's blue $(5 \times$ $10^{-3} \mathrm{~mol} \mathrm{~L}^{-1}$ ) was prepared by dissolving $0.223 \mathrm{~g}$ of Meldola's blue in double distilled water. Stock solution of sodium sulphate $30 \% \mathrm{w} / \mathrm{v}$ was prepared in double distilled water.

A double beam UV-visible spectrophotometer (UV-1800, Shimadzu, Japan) was used for measuring the absorbance and recording the spectra. A systronics digital $\mathrm{pH}$ meter 335 was used for $\mathrm{pH}$ measurements. A Remi R-24 centrifuge machine was used for centrifugation of samples.

Cloud point extraction: An aliquot solution containing appropriate amount of Meldola's blue solution at a pH of 4.5 with the concentrations from $0.0-11.17 \mu \mathrm{g} \mathrm{mL}^{-1}, 2.0 \mathrm{~mL}$ of 10 $\%$ w/v Triton X-114, $0.4 \mathrm{~mL}$ of $10 \% \mathrm{w} / \mathrm{v}$ docusate sodium salt and $0.8 \mathrm{~mL}$ of $30 \% \mathrm{w} / \mathrm{v} \mathrm{Na}_{2} \mathrm{SO}_{4}$ were taken in a centrifuge tube and diluted to $10 \mathrm{~mL}$ with double distilled water. The solution was kept at $70{ }^{\circ} \mathrm{C}$ in a thermostat bath for $25 \mathrm{~min}$, which resulted into two phases. Subsequently, complete phase separation was obtained through centrifugation and cooling for $15 \mathrm{~min}$ in an ice bath, then the supernatant aqueous phase was decanted. The surfactant rich phase (SRP) was dissolved in $20 \%$ methanol to decrease the viscosity and homogenized surfactant rich phase was analyzed spectrophotometrically at a wavelength of $568 \mathrm{~nm}$ for Meldola's blue dye.

\section{RESULTS AND DISCUSSION}

The absorbance of Meldola's blue in aqueous solution showed a maximum absorbance band at $568 \mathrm{~nm}$. Therefore, all the measurements were carried out at this wavelength. Meldola's blue was extracted into mixed micelles of Triton $\mathrm{X}-114$ and docusate sodium salt in the presence of sodium sulphate. For maximum extraction efficiency, the parameters affecting the cloud point extraction were optimized.

Optimization of pH: For optimization of $\mathrm{pH}$, buffers in the $\mathrm{pH}$ range from 1 to 8 were used. To maintain $\mathrm{pH}$ in the range from 1 to $8, \mathrm{KCl} / \mathrm{HCl}, \mathrm{CH}_{3} \mathrm{COONa} / \mathrm{CH}_{3} \mathrm{COOH}$ and $\mathrm{NaH}_{2} \mathrm{PO}_{4}$ $/ \mathrm{Na}_{2} \mathrm{HPO}_{4}$ buffers were used. A maximum recovery was observed for Meldola's blue with acetate buffer $\left(\mathrm{CH}_{3} \mathrm{COONa} / \mathrm{CH}_{3} \mathrm{COOH}\right)$ at a $\mathrm{pH}$ of 4.5. Therefore, $\mathrm{pH} 4.5$ was chosen for the extraction of Meldola's blue dye in subsequent experiments (Fig. 1).

Optimization of concentration of surfactants (Triton $\mathrm{X}-114$ and docusate sodium salt): Triton $\mathrm{X}-114$ is one of the non-ionic surfactants extensively used in cloud point extraction. This is due to its advantages such as low cost, high purity, low toxicity and commercial availability. Its high density and low cloud point temperature facilitating the easy phase separation of surfactant rich phase. The recovery of Meldola's blue dye was studied in the concentration range of Triton X-114 from $0.0 \% \mathrm{w} / \mathrm{v}$ to $3.0 \% \mathrm{w} / \mathrm{v}$. The recovery of Meldola's blue increased up to $2.0 \% \mathrm{w} / \mathrm{v}$ of Triton X-114 and then decreased. Thus, the optimum concentration of Triton X-114 was $2.0 \%$ w/v for Meldola's blue (Fig. 2).

To increase the recovery of the dye the anionic surfactant, docusate sodium salt has been used along with Triton X-114. The concentration of Triton X-114 $(2.0 \% \mathrm{w} / \mathrm{v})$ was fixed and the concentration of docusate sodium salt was optimized in the range from $0.0 \% \mathrm{w} / \mathrm{v}$ to $1.0 \% \mathrm{w} / \mathrm{v}$. The recovery increases

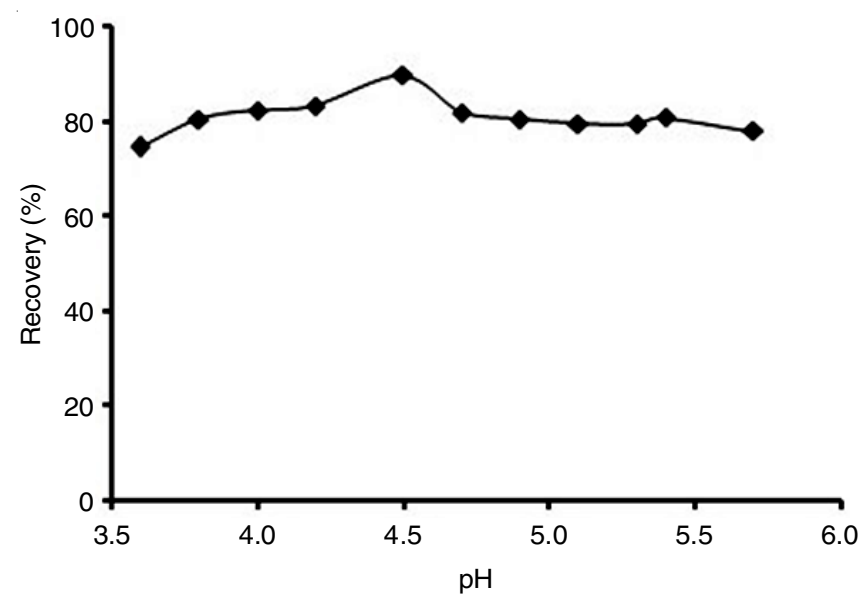

Fig. 1. Effect of $\mathrm{pH}$ on the recovery of Meldola's blue (experimental conditions: $2.0 \% \mathrm{w} / \mathrm{v}$ of TX-114; $0.4 \% \mathrm{w} / \mathrm{v}$ of docusate sodium salt; $2.4 \% \mathrm{w} / \mathrm{v}$ of $\mathrm{Na}_{2} \mathrm{SO}_{4}$; equilibration temperature $70{ }^{\circ} \mathrm{C}$; equilibration time $25 \mathrm{~min}$ )

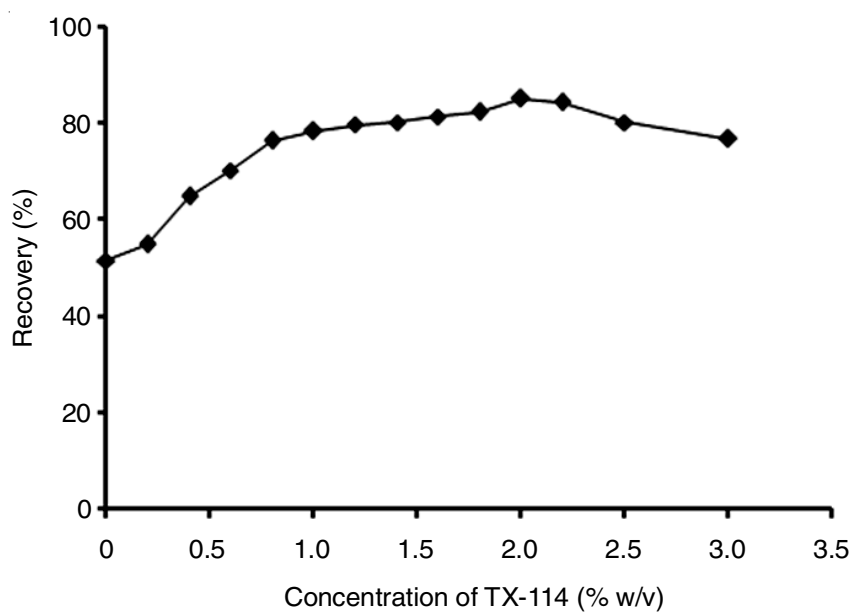

Fig. 2. Effect of concentration of TX-114 on the recovery of Meldola's blue (experimental conditions: $\mathrm{pH} 4.5 ; 0.4 \% \mathrm{w} / \mathrm{v}$ of docusate sodium salt; $2.4 \% \mathrm{w} / \mathrm{v}$ of $\mathrm{Na}_{2} \mathrm{SO}_{4}$; equilibration temperature 70 ${ }^{\circ} \mathrm{C}$; equilibration time $25 \mathrm{~min}$ )

up to $0.4 \% \mathrm{w} / \mathrm{v}$ of docusate sodium salt and then decreases. Thus, the optimum concentration of docusate sodium salt was found to be $0.4 \%$ w/v for Meldola's blue dye (Fig. 3).

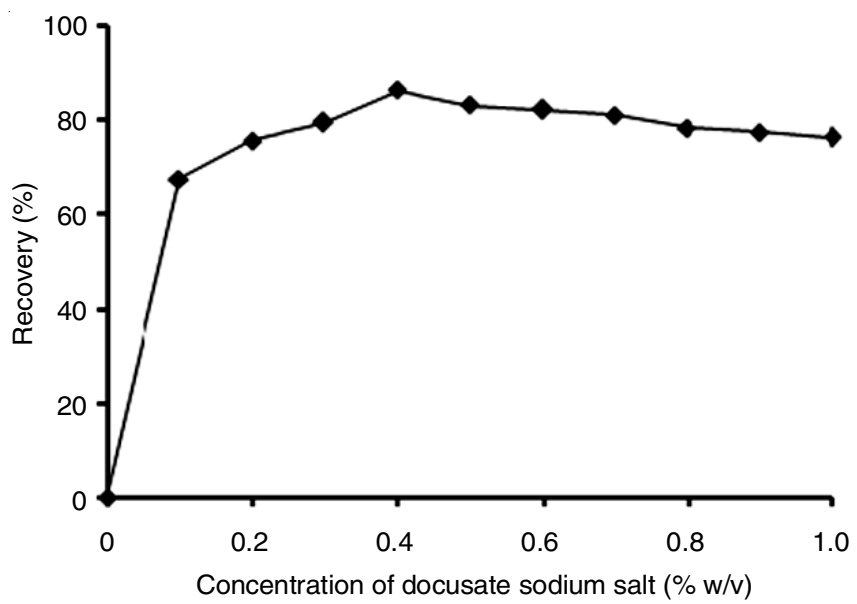

Fig. 3. Effect of concentration of docusate sodium salt on the recovery of Meldola's blue (experimental conditions: $\mathrm{pH} 4.5 ; 2.0 \%$ w/v of TX-114; $2.4 \% \mathrm{w} / \mathrm{v}$ of $\mathrm{Na}_{2} \mathrm{SO}_{4}$; equilibration temperature $70{ }^{\circ} \mathrm{C}$; equilibration time $25 \mathrm{~min}$ ) 
Optimization of concentration of $\mathrm{Na}_{2} \mathrm{SO}_{4}$ : The mixture of surfactants, Triton X-114 and docusate sodium salt are used for the extraction of dye has a cloud point temperature around $90-100^{\circ} \mathrm{C}$. To reduce the cloud point temperature and to achieve the phase separation of mixed surfactants, a salting out agent was used. The effect of several salting out agents like $\mathrm{NaCl}, \mathrm{NaNO}_{3}$ and $\mathrm{Na}_{2} \mathrm{SO}_{4}$ was determined and maximum recovery was observed in $\mathrm{Na}_{2} \mathrm{SO}_{4}$. The recovery of Meldola's blue dye was studied in the concentration range of $0 \% \mathrm{w} / \mathrm{v}$ to $6.0 \% \mathrm{w} / \mathrm{v}$. The recovery of dye increased with increasing the $\mathrm{Na}_{2} \mathrm{SO}_{4}$ concentration until $2.4 \% \mathrm{w} / \mathrm{v}$ for Meldola's blue dye and then the recovery was decreased. The optimum concentration of $\mathrm{Na}_{2} \mathrm{SO}_{4}$ was found to be $2.4 \%$ w/v for Meldola's blue dye (Fig. 4).

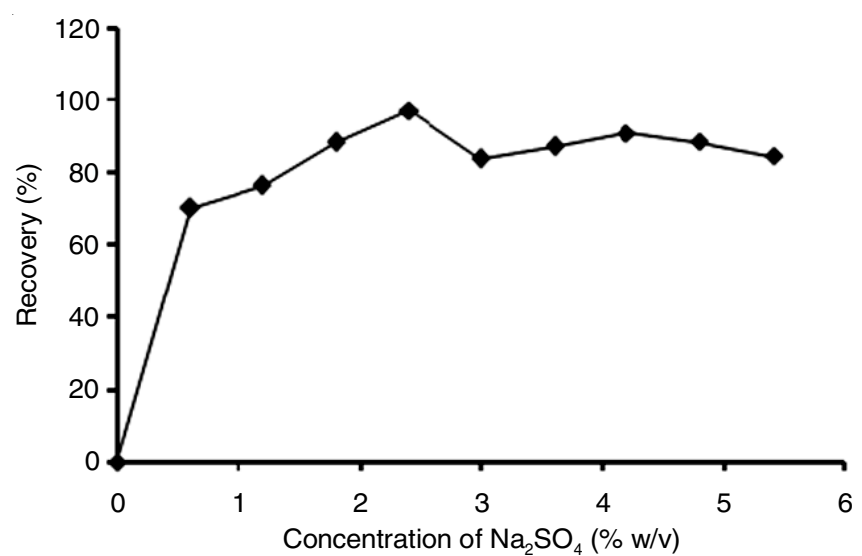

Fig. 4. Effect of concentration of $\mathrm{Na}_{2} \mathrm{SO}_{4}$ on the recovery of Meldola's blue (experimental conditions: $\mathrm{pH} 4.5 ; 2.0 \% \mathrm{w} / \mathrm{v}$ of TX-114; 0.4 $\% \mathrm{w} / \mathrm{v}$ of docusate sodium salt; equilibration temperature $70^{\circ} \mathrm{C}$; equilibration time $25 \mathrm{~min}$ )

Optimization of equilibration temperature and time: The phase separation for the mixed micelles of Triton X-114 and docusate sodium salt was not observed below $50{ }^{\circ} \mathrm{C}$ and the recoveries increased with increase in temperature up to 70 ${ }^{\circ} \mathrm{C}$ for Meldola's blue dye and then decreased. In the study of equilibration time, the recoveries increased up to $25 \mathrm{~min}$ and then decreased. Hence, the optimum equilibration temperature and time for Meldola's blue dye were found to be $70{ }^{\circ} \mathrm{C}$ and 25 min, respectively.

Analytical characteristics of the method: The analytical characteristics of the proposed method were evaluated under the optimized conditions. Calibration graph was drawn for Meldola's blue dye under the optimum conditions, from which the observed linearity range for Meldola's blue, was found to be $0.0-11.17 \mu \mathrm{g} \mathrm{mL}^{-1}$. The calibration equation obtained was $\mathrm{A}=0.075 \mathrm{C}_{\mathrm{MB}}+0.014$ with correlation coefficient of 0.998 . The limits of detection of Meldola's blue dye was $0.00311 \mu \mathrm{g}$ $\mathrm{mL}^{-1}$. The pre-concentration factor of the method was 20 and the extraction efficiency of the method was found to be $93.75 \%$.

Applications: The proposed mixed micellar cloud point extraction method was successfully applied for the extraction of Meldola's blue dye in tap and sea water samples. The spike recoveries were found to be in the range from $85.79-93.13 \%$. The results are given in Table-1.

\section{Conclusion}

The mixed micellar cloud point extraction method for the pre-concentration of Meldola's blue dye and its determination
TABLE-1

DETERMINATION OF MELDOLA'S BLUE IN THE REAL SAMPLES AND SPIKE RECOVERIES IN THE PRESENT DEVELOPED METHOD

\begin{tabular}{lccc}
\hline \multicolumn{1}{c}{ Samples } & $\begin{array}{c}\text { Spiked } \\
\left(\mu \mathrm{g} \mathrm{mL} L^{-1}\right)\end{array}$ & $\begin{array}{c}\text { Detected } \\
\left(\mu \mathrm{g} \mathrm{mL}^{-1}\right)\end{array}$ & Recovery $(\%)$ \\
\hline \multirow{3}{*}{ Tap water } & - & $\mathrm{ND}^{\mathrm{a}}$ & - \\
& 6.70 & 6.24 & 93.13 \\
& 8.94 & 7.85 & 87.80 \\
\hline \multirow{3}{*}{ Sea water } & - & $\mathrm{ND}^{\mathrm{a}}$ & - \\
& 6.70 & 5.78 & 86.26 \\
\hline${ }^{a}$ Not detected & 8.94 & 7.67 & 85.79 \\
\hline
\end{tabular}

with spectrophotometer in different water samples using mixed micelles of Triton X-114 and docusate sodium salt was successfully employed. The proposed cloud point extraction method is sensitive, selective, low cost and accurate, which allows the determination of Meldola's blue dye at $\mathrm{ng} \mathrm{mL}^{-1}$ level using spectrophotometry.

\section{ACKNOWLEDGEMENTS}

One of the authors (PS) is grateful to the Department of Science and Technology (DST-SERB), India for the financial support under the major research project SB/S1/IC-35/2013. Another author, SAK is also grateful to the University Grants Commission, India, for financial support under JRF scheme (Ref. No. 30092015118875).

\section{CONFLICT OF INTEREST}

The authors declare that there is no conflict of interests regarding the publication of this article.

\section{REFERENCES}

1. V. Manzo, O. Navarro, L. Honda, K. Sánchez, M. Inés Toral and P. Richter, Talanta, 106, 305 (2013);

https://doi.org/10.1016/j.talanta.2012.11.004

2. Q. Zhou, K. Zhao and A. Xing, J. Sep. Sci., 37, 3347 (2014); https://doi.org/10.1002/jssc.201400778.

3. A. Mittal, J. Mittal, A. Malviya, D. Kaur and V.K. Gupta, J. Colloid Interface Sci., 343, 463 (2010); https://doi.org/10.1016/j.jcis.2009.11.060.

4. H. Fu, C. Pan, W. Yao and Y. Zhu, J. Phys. Chem. B, 109, 22432 (2005); https://doi.org/10.1021/jp052995j.

5. A. Author, Analyst, 88, 864 (1963): https://doi.org/10.1039/an9638800864.

6. M. Soylak, Y.E. Ünsal, E. Yilmaz and M. Tüzen, Food Chem. Toxicol., 49, 1796 (2011);

https://doi.org/10.1016/j.fct.2011.04.030.

7. B. Xu, D. Song, Y. Wang, Y. Gao, B. Cao, H. Zhang and Y. Sun, J. Sep. Sci., 37, 1967 (2014);

https://doi.org/10.1002/jssc. 201400317

8. Z. Gao, T. Liu, X. Yan, C. Sun, H. He and S. Yang, J. Sep. Sci., 36, 1112 (2013);

https://doi.org/10.1002/jssc.201200835

9. P. Biparva, E. Ranjbari and M.R. Hadjmohammadi, Anal. Chim. Acta, 674, 206 (2010) https://doi.org/10.1016/j.aca.2010.06.024.

10. E. Heidarizadi and R. Tabaraki, Talanta, 148, 237 (2016); https://doi.org/10.1016/j.talanta.2015.10.075.

11. D. Duraimurugan, L. Mathuri, J. Indulekha, R. Anantharaj and A. Arunagiri, Biochem. Eng. Q., 30, 189 (2016); https://doi.org/10.15255/CABEQ.2014.2143.

12. N. Pourreza and Sh. Elhami, Environ. Chem. Lett., 8, 53 (2010); https://doi.org/10.1007/s10311-008-0190-x.

13. E. Ghasemi and M. Kaykhaii, J. Braz. Chem. Soc., 27, 1521 (2016); https://doi.org/10.5935/0103-5053.20160030.

14. A. Shokrollah and Z. Malekhosseini, Chem. Sci. Trans., 3, 37 (2014); https://doi.org/10.7598/cst2014.609.

15. A. Karatepe, Ç. Akalin and M. Soylak, Turk. J. Chem., 41, 256 (2017); https://doi.org/10.3906/kim-1606-45. 